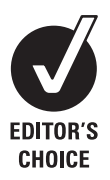

${ }^{1}$ National Blood Service, Birmingham, UK; ${ }^{2}$ National Blood Service, Oxford, UK; ${ }^{3}$ Clinical Evaluation and Effectiveness Unit, Royal College of Physicians, London, UK

Correspondence to:

Dr C Taylor, Consultant

Haematologist, National Blood

Service, Vincent Drive,

Edgbaston, Birmingham B15

2SG, UK; craig.taylor@nhs.net

Accepted 9 December 2007

\title{
Changes in practice and organisation surrounding blood transfusion in NHS trusts in England 1995- 2005
}

\author{
C J C Taylor, ${ }^{1}$ M F Murphy, ${ }^{2}$ D Lowe, ${ }^{3}$ M Pearson ${ }^{3}$
}

\begin{abstract}
Background: Between 1996 and 2005 in the UK, the Serious Hazards of Transfusion (SHOT) scheme has reported 105 deaths and 296 patients developing major morbidity due to transfusion. Accurate patient identification and monitoring of patients during blood transfusion are vital in ensuring patient safety, and national guidelines have been in place since 1999. There have been numerous initiatives in the UK in recent years promoting safe and appropriate use of blood and this paper reports the results of the 2005 National Comparative Audit of transfusion practice, and compares this audit with previous audits and survey results.
\end{abstract}

Methods: The 2005 audit consisted of two parts looking at organisational factors and bedside practice. To enable comparison with previous audits and surveys the 2005 data have been limited to English NHS sites (217 sites for organisational, 211 sites for bedside practice).

Results: Hospital transfusion committees were well established by 2003 though hospital transfusion teams have lagged behind. $86 \%$ of hospitals reported having established teams by 2005 although only $52 \%$ reported having all essential elements of the team in place. Only $38 \%$ reported having trained at least half of their nurses in blood transfusion. Bedside practice has improved, although in 2005, 6\% of patients receiving a blood transfusion had no identification wristband in place, and in $9 \%$ of those who did, the details were incomplete. Observation of vital signs during transfusions has also improved, although in 2005, 13\% of patients receiving a transfusion had had no observations recorded.

Conclusion: This paper document the progress that has been made in the UK in establishing an effective infrastructure for the support of safe transfusion practice, and the measurable improvements in bedside transfusion practice. There remain, however, many areas of poor practice, and the improvements have not been seen across all hospitals. It is still too early to say whether progress made is being translated into a reduction in serious transfusion errors at the bedside. Further progress needs to be made.

The risks associated with receiving a blood transfusion are well known. In the decade to 2005, reports to the Serious Hazards of Transfusion (SHOT) scheme documented 105 deaths and 296 patients experiencing major morbidity due to transfusion. ${ }^{1}$ The public often perceive transmission of disease to be the most important transfusion risk but the reality is that the most serious risks are related to potentially avoidable human errors.
The most important risk is receiving a unit of blood intended for another patient, and since 1996 there have been 203 reports of $\mathrm{ABO}$ incompatible red cell transfusions (the most dangerous type of wrong transfusion). Six of the patients died as a direct result of this error. In nine cases, $A B O$ incompatible transfusion was a contributory factor to the death of the patient, and another 54 patients had major morbidity. Such incidents can result from misidentification of the patient, blood sample or blood unit at any point in the process, from taking the blood sample for compatibility testing, errors in the laboratory or in the collection of the blood unit, to administering the blood to the patient.

National guidelines have been in place since 1999 on the procedures for safe administration of blood and these form the basis of most hospital transfusion policies. ${ }^{2}$ These guidelines aim to ensure positive patient identification through checks at each stage of the transfusion process, and proactive monitoring of patients during transfusion to alert staff to a developing adverse reaction.

The Department of Health issued a Health Service Circular (HSC) on "better blood transfusion" in 1998 (HSC 1998/224), with a focus on improving the safety of blood transfusion in hospitals. HSC 1998/224 directed hospitals in how transfusion services should be structured to ensure quality and safety for the patient. A second document on better blood transfusion was issued in 2002 (HSC 2002/009) ${ }^{4}$ which built on the first, with expanded recommendations to include initiatives on the appropriate use of blood.

Since the first HSC there has been a great deal of change in the UK with the establishment of the national and regional blood transfusion committees and the development of services from within the National Blood Service to support hospitals in their efforts to comply with recommendations for good transfusion practice. There have followed numerous initiatives to raise the profile of the safety issues (table 1), and the National Patient Safety Agency (NPSA) has set a target of reducing $\mathrm{ABO}$ incompatible transfusions by $50 \%$ within the next 3-5 years. ${ }^{8}$

The blood transfusion process in the UK was first audited in 50 hospitals in 1995 in a collaboration between the Royal College of Physicians, British Society of Haematology, British Blood Transfusion Society and the Royal College of Pathologists. 'This was repeated in $1998^{\circ}$ in 23 hospitals and the results informed a symposium held by the chief medical officers of the UK, giving 
Table 1 Some of the national initiatives aimed at improvements in transfusion safety

\begin{tabular}{|c|c|}
\hline \multirow{3}{*}{$\begin{array}{l}\text { Chief Medical Officer/Department of } \\
\text { Health initiatives }\end{array}$} & Better blood transfusion (HSC 1998/224) ${ }^{3}$ \\
\hline & Better blood transfusion: appropriate use of blood (HSC 2002/009) \\
\hline & $\begin{array}{l}\text { Development of an integrated blood shortage plan for the National Blood Service and } \\
\text { Hospitals, } 2004 \text { (Chief Medical Officer's National Blood Transfusion Committee) }{ }^{5}\end{array}$ \\
\hline \multirow[t]{2}{*}{ Guidelines } & $\begin{array}{l}\text { "The administration of blood and blood components and the management of } \\
\text { transfused patients" (Guidelines of the British Committee for Standards in } \\
\text { Haematology) }\end{array}$ \\
\hline & Right blood, right patient, right time (Royal College Nursing, 2004) \\
\hline Haemovigilance & SHOT $^{1}$ - participation still growing \\
\hline \multirow[t]{2}{*}{ Audit } & National Comparative Audit programme ${ }^{7}$ \\
\hline & Regional seminars on results of 2003 audit \\
\hline \multirow[t]{2}{*}{ Training packages } & $\begin{array}{l}\text { Better Blood Transfusion Continuing Education Programme (Scottish National Blood } \\
\text { Transfusion Service; http://www.learnbloodtransfusion.org.uk; accessed } 11 \text { Jun } \\
\text { 2008) }\end{array}$ \\
\hline & $\begin{array}{l}\text { Learn Cell Salvage (Trent Transfusion Alternatives Group } \\
\text { http://www.transfusionguidelines.org.uk/lcs/index.htm; accessed } 11 \text { Jun 2008) }\end{array}$ \\
\hline National Patient Safety Agency & Right patient, right blood (Safer Practice Notice) ${ }^{8}$ \\
\hline $\begin{array}{l}\text { Clinical Negligence Scheme for } \\
\text { Trusts/NHS Litigation Authority }\end{array}$ & Demands training is in place and documented (level 2) \\
\hline $\begin{array}{l}\text { Clinical governance developments in } \\
\text { hospitals }\end{array}$ & \\
\hline
\end{tabular}

SHOT, Serious Hazards of Transfusion.

rise to HSC 1998/224 and an update of the British Committee for Standards in Haematology guidelines for the administration of blood in 1999. Since then the audit has been further developed by the National Comparative Audit of Blood Transfusion group, and the audit was repeated nationwide in $2003^{10}$ and 2005. ${ }^{11}$ In parallel with these audits, hospitals progress with the implementation of HSC 1998/224 and HSC 2002/009 has been surveyed by the National Blood Transfusion Committee in 2001, ${ }^{12} 2003^{13}$ and 2004. ${ }^{13}$ There are now considerable data in this area. In the present study, we compared the results of the 2005 national audit with preceding audits and surveys to determine whether there have been measurable improvements in practice that mirror the ongoing initiatives and organisational changes surrounding blood transfusion in NHS trusts in England.

\section{METHODS}

The 2005 National Comparative Audit of the Blood Transfusion process was in two parts, a questionnaire on organisational aspects of transfusion and a prospective audit of bedside transfusion practice. Hospitals were invited to take part if they transfused more than 5 units of blood a week. Of 280 eligible NHS English hospitals, 223 (80\%) participated in the organisational audit, $214(76 \%)$ in the audit of transfusion episodes, and $199(71 \%)$ in both parts. A few hospitals submitted combined data so that results for England were summarised for 217 hospital sites (organisational) and 211 hospital sites (episodes). Results are given in both the text and tables for these hospital sites. Data were collected between March and July 2005.

Where possible we have limited the results to English NHS hospitals, to enable like with like comparisons between audits and with other surveys. The 1995 audit included 50 hospitals, 44 of which were English NHS hospitals. The 1998 audit involved 23 of the same hospitals (20 England, 2 Wales, 1 Northern Ireland), but due to the aggregate nature of surviving records it was only possible to summarise the overall data. The 2003 bedside audit, also observational and prospective, reported data from 160 NHS hospitals in England.

Organisational data from the 2005 audit has been compared with published data from surveys of hospital implementation of HSCs 1998/224 and 2002/009. The surveys were sent to NHS hospitals supplied by the National Blood Service ${ }^{12}{ }^{13}$ in England and parts of north Wales.

The sample structure varied between the audits. In 1995 only medical inpatients were included whereas in 1998, all patients receiving transfusions were eligible regardless of clinical area. The 2003 and 2005 audits used a quota system so that hospital samples were representative of usual blood usage. There were some minor variations in the wording of questions between audits, but these are unlikely to have resulted in major bias in the data presented.

\section{RESULTS}

\section{Organisation and infrastructure}

Table 2 shows the details of the organisation and infrastructure of hospital transfusion services. Hospital transfusion committees (HTCs) were well established by 2003, but appointment of transfusion practitioners and establishment of hospital transfusion teams (HTTs) have lagged behind. Although 91\% (196/215) had a lead consultant, a quarter of these (42/155, unstated for 41) reported having no designated time for the role.

Of sites with an HTT (187/217), only 52\% (80/155, insufficient information for 32 ) reported having a transfusion practitioner in post as well as a consultant with dedicated time and attendance at least once in the year by each of the core members (transfusion practitioner, consultant and blood bank manager). The other $48 \%(75 / 155)$ of the sites did not have all these features. Of these 75, 42 reported attendance from all core members, despite 21\% (9/42) having no clinical lead and 69\% (29/42) having a clinical lead with no time for the role. 
Table 2 Comparison of transfusion infrastructure in English NHS hospitals between 1995 and 2005

\begin{tabular}{|c|c|c|c|c|c|c|c|c|c|c|c|c|}
\hline \multirow[b]{2}{*}{ Sites with data } & \multicolumn{2}{|c|}{$1995^{9}$} & \multicolumn{2}{|c|}{$1998^{9}$} & \multicolumn{2}{|c|}{$2001 * 12$} & \multicolumn{2}{|c|}{$2003^{* 13}$} & \multicolumn{2}{|c|}{$2004^{* 13}$} & \multicolumn{2}{|c|}{$2005 \uparrow^{11}$} \\
\hline & 44 & & 18 & & 220 & & 122 & & 160 & & 217 & \\
\hline & $\%$ & $\mathrm{n}$ & $\%$ & $\mathrm{n}$ & $\%$ & $\mathrm{n}$ & $\%$ & $\mathrm{n}$ & $\%$ & $\mathrm{n}$ & $\%$ & $\mathrm{n}$ \\
\hline Hospital transfusion committee & 78 & $32 / 41$ & 78 & 14 & 91 & NA & 98 & NA & 99 & NA & 99.5 & 216 \\
\hline Hospital transfusion team & - & & - & & - & & 76 & NA & 84 & NA & 86 & 187 \\
\hline Transfusion practitioner in post & - & & - & & 14 & NA & 50 & NA & 68 & NA & 82 & $176 / 215$ \\
\hline Lead consultant & - & & - & & - & & 74 & NA & 83 & NA & 91 & $196 / 215$ \\
\hline Have policies for transfusion & 93 & $39 / 42$ & 94 & 17 & 98 & NA & 97 & NA & 98 & NA & - & \\
\hline
\end{tabular}

${ }^{*}$ NHS hospitals supplied by National Blood Service_-includes England and North Wales.

$\dagger$ Data given for English NHS hospitals only.

NA, denominator data not available.

Only 38\% (79/206) of hospitals in 2005 reported provision of annual retraining to at least half of its nurses.

\section{Bedside practice}

Table 3 shows the results of audits of bedside transfusion practice from 1995 to 2005. More patients were wearing a wristband, and from 2003 to 2005 the completeness of patient identification details on the wristband improved. In terms of site variation of results for 2005 the 10-90th centile range was $83-100 \%$ indicating that $10 \%$ of sites had $83 \%$ or fewer audit patients wearing wristbands. The 10-90th centile range for completeness of detail on the wristband was $77-100 \%$.

The recording of pretransfusion observations has improved since 2003, and in 2005 was being done in the majority of cases (10-90th centile range: $75-100 \%)$. The percentage of patients with observations recorded in the first $30 \mathrm{~min}$ of transfusion improved, but by 2005 , $35 \%$ of transfused patients still had no record of the pulse being recorded and $13 \%$ of patients (10-90th centile range: $0-34 \%$ ) had no record of transfusion-related observations.

Restricting analysis to the 148 English NHS hospitals that participated in both 2003 and 2005 (table 4) yielded figures that are almost identical to those in table 3 . Similar trends were also seen in the results for the 24 hospitals that participated in the 1995, 2003 and 2005 audits (table 5).

\section{DISCUSSION}

Donabedian observed in 1966 that the best outcomes depend on good processes of care which in turn depend on the correct structures and organisation being in place ${ }^{14}$ Observations from the national audit in stroke care ${ }^{15}$ and chronic obstructive pulmonary disease ${ }^{16}$ support this and in transfusion it is not unreasonable to begin by examining the structures in hospitals. The 2005 audit is the largest and most complete survey of its kind with over $80 \%$ of NHS trusts taking part and is likely to be a representative picture. In parallel with the organisational audit, data were collected on the process of blood transfusion in the clinical areas. Again, the large sample gives confidence that this is likely to be a representative picture of UK hospitals in 2005.

The 2005 national audit follows a series of smaller studies and we have attempted to compare results over the years. The comparisons made within the same hospitals give a similar picture to the whole sample and we believe that the trends observed are likely to be a reflection of practice as a whole.

There has been a concerted effort with many specific initiatives from the Department of Health and the blood transfusion services aimed at improving the quality of blood transfusion and eliminating transfusion-related mortality and morbidity, and a key recommendation has been that each hospital should have an HTT as a vital starting point. ${ }^{34}$

Table 3 Comparison of bedside transfusion practice between 1995 and 2005 for English NHS hospital sites (1998 data include two Welsh and one Northern Ireland site)

\begin{tabular}{|c|c|c|c|c|c|c|c|c|}
\hline & \multicolumn{2}{|l|}{$1995^{9}$} & \multicolumn{2}{|l|}{$1998^{9}$} & \multicolumn{2}{|l|}{$2003^{10}$} & \multicolumn{2}{|l|}{$2005^{11}$} \\
\hline Sites & 44 & & $23^{*}$ & & 160 & & 211 & \\
\hline \multirow[t]{2}{*}{ Cases } & 2088 & & 979 & & 5014 & & 6764 & \\
\hline & $\%$ & $\mathrm{n}$ & $\%$ & $\mathrm{n}$ & $\%$ & $\mathrm{n}$ & $\%$ & $\mathrm{n}$ \\
\hline With wristband & & $\dagger$ & 72 & 700 & 90 & 4516 & 94 & 6337 \\
\hline $\begin{array}{l}\text { Wristbands with complete surname, } \\
\text { first name, date of birth, identification } \\
\text { number }\end{array}$ & & & & $t$ & 86 & $3864 / 4516$ & 91 & $5790 / 6337$ \\
\hline In side room/bay on own & & & 27 & $265 / 970$ & 25 & $1246 / 4953$ & 22 & $1380 / 6408$ \\
\hline $\begin{array}{l}\text { With pretreatment observations } \\
\text { recorded }\end{array}$ & & & & & & & & \\
\hline Temperature & 78 & $1576 / 2030$ & 89 & $841 / 950$ & 74 & $3724 / 5013$ & 90 & $6032 / 6702$ \\
\hline Pulse & 77 & $1568 / 2030$ & 87 & $829 / 950$ & 76 & $3830 / 5013$ & 91 & $6078 / 6691$ \\
\hline Blood pressure & 75 & $1517 / 2031$ & 81 & $765 / 950$ & 75 & $3758 / 5013$ & 91 & $6092 / 6690$ \\
\hline With temperature $\leqslant 30 \mathrm{~min}$ & 49 & $938 / 1900$ & First & $\mathrm{T}$ or $\mathrm{P}$ & 58 & 2907 & 64 & 4326 \\
\hline With pulse $\leqslant 30 \mathrm{~min}$ & 51 & $959 / 1891$ & 57 & $520 / 919$ & 59 & 2973 & 65 & 4371 \\
\hline $\begin{array}{l}\text { With no observations during treatment } \\
\text { at all }\end{array}$ & 14 & $\begin{array}{l}\mathrm{T}(272 / 2006) \\
\mathrm{P}(277 / 2003)\end{array}$ & 9 & 90 & 12 & 610 & 13 & 890 \\
\hline
\end{tabular}

*Includes two Welsh and one Northern Irish hospital.

$\uparrow 1995$ audit did not audit wristbands.

$\$ 1998$ audit did not ask what was written on wristbands.

$\mathrm{T}$, temperature; $\mathrm{P}$, pulse. 
Table 4 Comparison of 148 English NHS hospital sites taking part in both the 2003 and 2005 audits

\begin{tabular}{lrrrr}
\hline & $\mathbf{2 0 0 3}^{\mathbf{1 0}}$ & $\mathbf{2 0 0 5}^{\mathbf{1 1}}$ & \\
\hline Sites & 148 & 148 & \\
Cases & 4556 & 4616 & \\
& $\%$ & $\mathrm{n}$ & $\%$ & $\mathrm{n}$ \\
With wristband & 90 & 4097 & 94 & 4352 \\
Wristbands with complete surname, & 85 & $3481 / 4097$ & 91 & $3966 / 4352$ \\
first name, date of birth, identification & & & & \\
number & & & & \\
In side room/bay on own & 25 & $1119 / 4513$ & 22 & $992 / 4410$ \\
With pretreatment observations recorded & & & & \\
$\quad$ Temperature & 74 & $3373 / 4555$ & 90 & $4115 / 4580$ \\
$\quad$ Pulse & 76 & $3466 / 4555$ & 91 & $4148 / 4572$ \\
$\quad$ Blood pressure & 75 & $3410 / 4555$ & 91 & $4153 / 4569$ \\
With temperature $\leqslant 30$ min & 59 & 2672 & 66 & 3057 \\
With pulse $\leqslant 30$ min & 60 & 2736 & 67 & 3079 \\
With no observations during treatment & 12 & 537 & 12 & 556 \\
at all & & & & \\
\hline
\end{tabular}

\section{Infrastructure}

An HTT is a relatively simple structure to establish. Despite this nearly half of the hospitals lacked one or more of a transfusion practitioner in post, consultant with dedicated time, or attendance by the core members at least once in the preceding year. Implementation of any policy across an organisation requires leadership, and that leader has to have allocated time for the task. The lack of clinical leadership in so many hospitals is a cause for concern. Similarly, the transfusion practitioner is a key link to training the many clinical staff involved in the practical aspects of safe and appropriate transfusion, and an essential member of the team. One has to question how well those teams that lack these key elements of the HTT are functioning.

The progress that has been made should not be belittled, and the successes only serve to remove excuses from those trusts whose infrastructures remain incomplete. The results in blood transfusion mimic other audit data. The Royal College of Physicians stroke audit showed a lead physician in fewer than half of hospitals in 1998 rising to $96 \%$ in 2004, and with better organisation, improvements in delivery of care were seen. ${ }^{17}$

SHOT reports show that adverse incidents often arise from omission of simple checks. One of the duties therefore of the
HTT is to ensure that the many staff administering transfusions are properly trained. It is alarming therefore to find that training of nurses remains so poor.

\section{Improvements in bedside practice and patient safety}

Once again progress should not be belittled, but in 2005, 6\% of patients receiving a transfusion had no form of patient identification (wristband or equivalent), and 13\% had no transfusion-related observations recorded. These are basic aspects of patient safety and these simple failures continue to place patients at risk.

The most serious transfusion reaction occurs when a patient is given an $A B O$ incompatible red cell transfusion intended for someone else. The NPSA has set a target of reducing such transfusions by $50 \%$ over the next few years. The 2005 SHOT report showed the first convincing signs of improvements with a fall in absolute numbers of $\mathrm{ABO}$ incompatible transfusions. However, this must be viewed in the context of a fall in the total number of units of red blood cells transfused in the UK of $16 \%$ in the past 6 years.

\section{What next?}

All hospitals should implement HSC 2002/009 fully, and establish quality systems for clinical transfusion practice. Each hospital should establish an effective infrastructure to support and develop its systems and to ensure effective training is provided to all relevant staff. This is more than simply setting up or having a hospital transfusion committee. Implementing better practice across multiple specialities in multiple settings across a hospital requires an active process of engagement and monitoring by managers and clinicians working together. It may be advantageous to examine the systems in the more successful hospitals in this audit, which demonstrate that implementation of HSC 2002/009 recommendations is possible. Their success makes it even more important for those hospitals that are not, to re-examine urgently their organisation and training.

The failings in bedside processes are generally down to human error. The majority of hospitals continue to rely on manual, paper systems for checking the identity of the patient and the unit of blood. There is a limit to the reliability of these systems, and even experienced staff with perfect training records may make mistakes or take shortcuts when under pressure.

Table 5 Comparison of 24 English NHS hospital sites taking part in the 1995, 2003 and 2005 audits

\begin{tabular}{|c|c|c|c|c|c|c|}
\hline & $1995^{9}$ & & $2003^{10}$ & & $2005^{11}$ & \\
\hline Sites & 24 & & 24 & & 24 & \\
\hline \multirow[t]{2}{*}{ Cases } & 1150 & & 860 & & 798 & \\
\hline & $\%$ & $\mathrm{n}$ & $\%$ & $\mathrm{n}$ & $\%$ & $\mathrm{n}$ \\
\hline With wristband & & & 91 & 781 & 94 & 753 \\
\hline $\begin{array}{l}\text { Wristbands with complete surname, } \\
\text { first name, date of birth, identification } \\
\text { number }\end{array}$ & & & 87 & $677 / 781$ & 91 & $683 / 753$ \\
\hline In side room/bay on own & & & 22 & $185 / 849$ & 18 & $141 / 780$ \\
\hline \multicolumn{7}{|l|}{ With pretreatment observations recorded } \\
\hline Temperature & 81 & $898 / 1113$ & 74 & 635 & 90 & $708 / 785$ \\
\hline Pulse & 81 & $903 / 1114$ & 75 & 646 & 92 & $716 / 782$ \\
\hline Blood pressure & 77 & $857 / 1116$ & 75 & 642 & 91 & $712 / 782$ \\
\hline With temperature $\leqslant 30 \mathrm{~min}$ & 54 & $572 / 1069$ & 62 & 534 & 65 & 519 \\
\hline With pulse $\leqslant 30$ min & 55 & $588 / 1071$ & 63 & 538 & 66 & 525 \\
\hline With no observations during treatment at all & 16 & $\begin{array}{l}\mathrm{T}(175 / 1113) \\
\mathrm{P}(184 / 1113)\end{array}$ & 8 & 70 & 16 & 126 \\
\hline
\end{tabular}

\footnotetext{
$T$, temperature; $P$, pulse.
} 
Electronic systems with the potential to improve safety for the patient, ${ }^{18}{ }^{19}$ are available and the NPSA has called on hospitals to consider the implementation of such systems. ${ }^{8}$ As correct patient identification has a key place in ensuring patient safety, these systems have potential benefit that reach far beyond blood transfusion.

There has been measurable progress and improvement both in the provision of an adequate blood transfusion infrastructure and in bedside transfusion practice in hospitals. However, it cannot be acceptable for patients to still be put at risk of incompatible transfusions for lack of simple identification and procedure monitoring.

Acknowledgements: We thank all of the hospital staff who supplied data for the 2005 audit of the transfusion process.

Funding: The National Comparative Audit of Blood Transfusion programme is a collaboration between the Royal College of Physicians, London and the National Blood Service. The programme is funded by the National Blood Service.

Competing interests: None.

\section{REFERENCES}

1. Serious Hazards of Transfusion. Annual reports from 1996 to 2005. Manchester, UK: Serious Hazards of Transfusion Scheme. http://www.shotuk.org laccessed 6 Jun 2008).

2. British Committee for Standards in Haematology, Blood Transfusion Task Force. Royal College of Nursing and the Royal College of Surgeons of England. The administration of blood and blood components and the management of transfused patients. Transfus Med 1999:9:227-39. http://www.bcshguidelines.com/pdf/ tme203.pdf (accessed 6 Jun 2008).

3. Department of Health. Better blood transfusion. London: DH, 1998 (HSC 1998/224). http://www.dh.gov.uk/assetRoot/04/01/19/19/04011919.pdf (accessed 6 Jun 2008).

4. Department of Health. Better blood transfusion: appropriate use of blood. London: DH, 2002 (HSC 2002/009). http://www.dh.gov.uk/assetRoot/04/01/22/93/04012293. pdf (accessed 6 Jun 2008).

5. Chief Medical Officer's National Blood Transfusion Committee. Development of an integrated blood shortage plan for the National Blood Service and Hospitals,
2004. http://www.blood.co.uk/hospitals/library/pdf/ESD PCS HL 001 01.pdf (accessed 6 Jun 2008).

6. Royal College of Nursing. Right blood, right patient, right time. RCN guidance for improving transfusion practice, 2004. Search via http://www.rcn.org.uk (accessed 11 Jun 2008)

7. NHS Blood and Transplant. National comparative audit of blood transfusion. http:// www.blood.co.uk/hospitals/safe use/clinical audit/National Comparative/index.asp (accessed 6 Jun 2008).

8. National Patient Safety Agency. Right patient, right blood. Safer Practice Notice NPSA/2006/14. Search via http://www.npsa.nhs.uk (accessed 6 Jun 2008).

9. Murphy MF, Wilkinson J, Lowe D, et al. National audit of the blood transfusion process in the UK. Transfus Med 2001;11:363-70.

10. National Blood Service and Royal College of Physicians London. National comparative audit of blood transfusion. Birmingham: National Comparative Audit of Blood Transfusion, 2003. http://www.blood.co.uk/hospitals/library/pdf/safe use/ 2003 aud rep.pdf (accessed 6 Jun 2008).

11. National Blood Service and Royal College of Physicians London. National comparative audit of blood transfusion. Re-audit of bedside transfusion practice. Birmingham: National Comparative Audit of Blood Transfusion, 2005. http://www. blood.co.uk/hospitals/library/pdf/safe use/2005 aud rep.pdf (accessed 6 Jun 2008)

12. Murphy MF, Edbury C, Wickenden ${ }^{C}$. Survey of the implementation of the recommendations in the Health Services Circular 1998/224 "Better blood transfusion". Transfus Med 2003:13:121-5.

13. Murphy MF, Howell C. Survey of the implementation of the recommendation in the Health Services Circular 2001/009 "Better blood transfusion". Transfus Med 2005:15:453-60.

14. Donabedian A. Evaluating the quality of medical care. Millbank Mem Fund 0 1966:44(3 Suppl):166-206.

15. Rudd AG, Irwin P. Rutledge Z, et al. Regional variations in stroke care in England, Wales and Northern Ireland: results from the National Sentinel Audit of Stroke. Royal College of Physicians Intercollegiate Stroke Working Party. Clin Rehabil 2001;15:562-72.

16. Price L, Lowe D, Hosker H, et al. The UK National COPD Audit 2003: impact of hospital resources and organisation of care on patient outcome following admission for acute COPD exacerbation. Thorax 2006;61:837-42.

17. Rudd AG, Hoffman A, Down C, et al. Access to stroke care in England, Wales and Northern Ireland: the effect of age, gender and weekend admission. Age Ageing 2007:36:247-55

18. Turner CL, Casbard A, Murphy MF. Barcode technology: its role in increasing the safety of transfusion. Transfusion 2003;43:1200-9.

19. Davies A, Staves J, Kay J, et al. End-to-end electronic control of the hospita transfusion process to increase the safety of blood transfusion: strengths and weaknesses. Transfusion 2006:46:352-64. 